\title{
Mõned armsad vanad jutud jõuludeks noortele ja vanadele lugeda
}

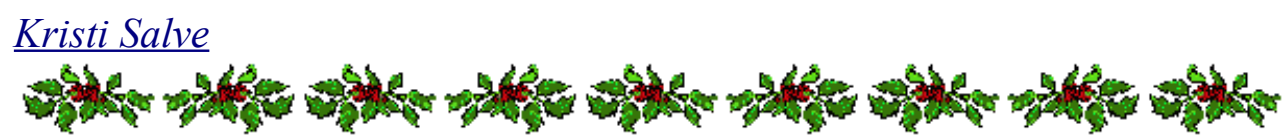

Jönkadi-jönkadi - või kuidagi teistmoodi, aga - jõulud tulevad. Me tarvitame seda sõna mitmuses nagu mõnede teistegi kalendripühade ja inimese elutähtpäevade nimetusi -vastlad, nelipühad, pulmad, matused. Kui pisut mõelda, selgub, et osa neist on küll kestnud rohkem kui ühe päeva, aga mitte kõik, nõnda et mitmuse tarvitamine pole niisama lihtsalt seletatav.

Kui nüüd tahta veidi mängida, siis võib öelda, et tulemas ongi mitmed erinevad, kuid ajalt kokkulangevad pühad. Tänapäeva Eesti kristlikule vähemusele on see Jeesuse sünnipäev, suurele osale rahvast rahvakalendri keskne tähtpäev oma traditsiooniliste toitude, lähedaste (ka lahkunute) meelespidamise ja muu säärasega, eelmiste kõrval saavad aina tähtsamaks eurojõulud ehk kaubanduslikud jõulud oma päkapikkude, laviinina pealetuleva reklaami ja sellest inspireeritud ostupalavikuga.

Mäetagustele eurojõulud siiski suuremat korda ei lähe. Rahvalikud jõulud, mis on meie huvikeskmes, on küll omaettegi liiga lai teema. Kitsendame siis seda ja pakume kimbukese jõulujutte. See pole teaduslik termin. Järgnevatest juttudest mõned seostuvad jõuludega tegevusaja kaudu, teised jälle seetõttu, et tegelaseks on Jeesus, kolmandad on valitud pelgalt neis sisalduvate kristlike elementide pärast.

Esimeses muinasjutus manifesteerub jõuluöö imede ööna.
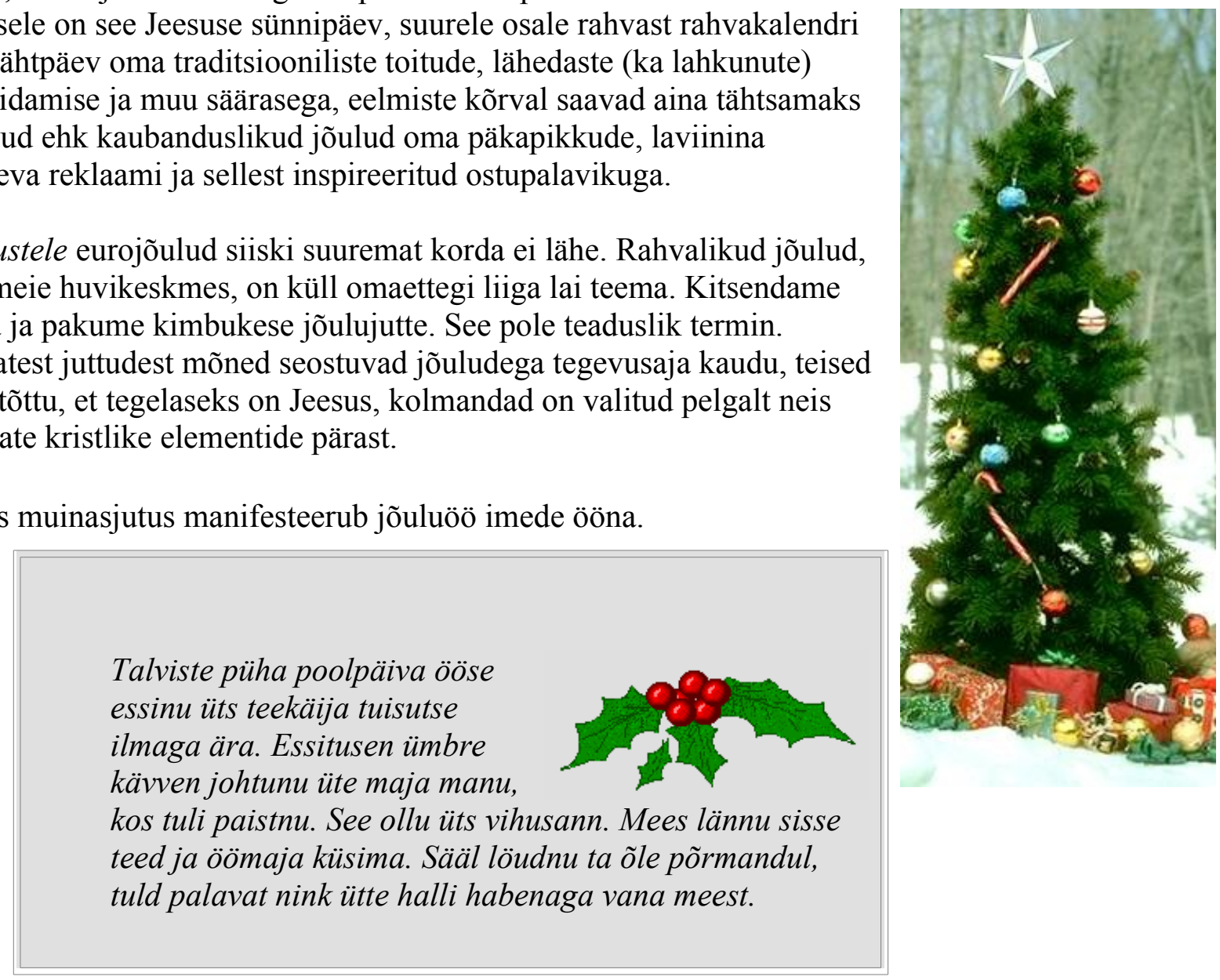

Kas on raskevõitu mõista? Ja mis talviste pühadest siin üldse juttu on, lubati ju jõuludest jutustada? Talviste või taliste või talsipüha on vana lõunaeesti sõna jõulude tähenduses, ja sel on selge etümoloogia - need on ju talvise aja pühad - vastandina suvistele. Küllap seda tarvitati kunagi ammu ka Põhja-Eestis, aga siis hakkas levima skandinaavialaenuline (tänapäeva rootsi keeles $j u l$ ) jõulusõna - nagu Soomeski. Lõunaeestlased aga säilitasid viimase ajani oma muistse nimetuse, vähemalt vanad inimesed tarvitasid seda veel mõnekümne aasta eest. 
Aga hakkame siiski muinasjutuga uuesti otsast peale - põhjaeesti kirjakeeles.

Jõululaupäeva öösi eksinud üks teekäija tuisuse ilmaga ära. Eksinult ringi käies jõudnud ta ühe maja juurde, kus tuli paistnud. See olnud vihusaun. Mees läinud sisse teed ja öömaja küsima. Seal leidnud ta õled põrandal, tule põlemas ning ühe halli habemega vanamehe. Teekäija küsinud vanamehe käest, kas ta ei võiks siia ööseks jääda, sest ta ise ja ta hobune olevat teekäigust väsinud ning ilm väga tuisune. Ta mõtelnud, et siin oleks õige hea soojas saunas külmetanud konte puhata.

Vanamees kostnud: "Mine enne mäele toa juurde ning vaata, kas seal on kõik vagane." Mees läinud ja näinud rehealuse läve ees verist hobuseraibet maas. Majja sisse minnes leidnud ta kõik magavat. Ühe abielupaari suude ümber näinud ta liblikat lendavat, teisel paaril käinud madu ühe suust teise suhu.

Väljas kuulnud ta oigamist ning hõikamist: "Korja mind, tõsta mind!" Kui rändaja sauna juurde tagasi tulnud, ütelnud vanamees: "Hobuse võid sauna eeskotta panna, ega siin varast ega murdjat ei ole." Mees võtnud hobuse lahti ja pannud sööma.

Saunas küsinud vanamees: "Mis sa seal mäel nägid?"

Nü̈̈d seletanud mees, mis ta näinud ja kuulnud: et hobuseraibe olnud läve ees, et ühtedel lennanud liblikas ja teistel käinud madu suust suhu

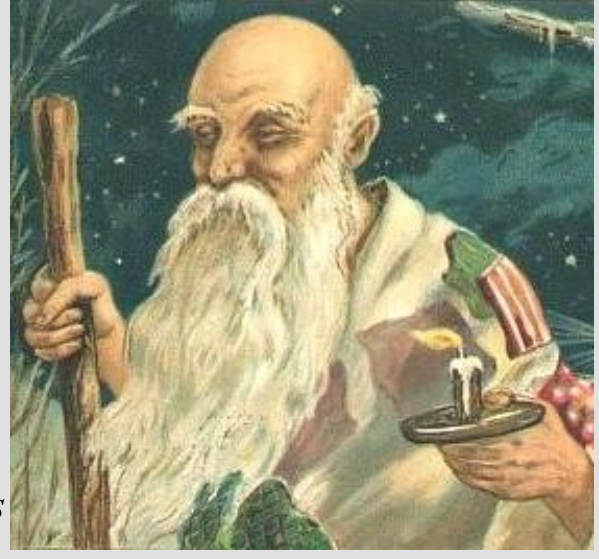
ning et väljas kostis hõikamist.

Seepeale seletanud vanamees teekäijale nõnda: " Hobuseraibe tähendab seda, et kõik hobuseriistad on kallil ööl seina veeres vedelemas ja reed väljas lume sees.

Paar, kelle suude ümber liblikas lendleb, elab jumalakartlikku elu ning on ingli valve all. Need, kellel madu suust suhu käib, on kurja täis. Nad riidlevad ja sõimlevad teineteisega ühtevalu.

Seda häält, mida sa väljas kuulsid, teevad need viljapead ja terad, mis hooletuse ja laiskuse pärast on maha jäetud."

Nü̈d heitnud mees sauna lavale õlgede peale ja jäänud magama. Hommikul, kui ta üles ärganud, leidnud ta ennast palja lava peal magavat, viht pea all. Pole olnud õlgi, pole olnud näha tuld ega vanameest - kõik olnud kadunud.

Mees pannud oma hobuse ette ning läinud jälle oma teed. H II 30, 897/9 (1) < Rõngu khk - A. Rahi (1889)

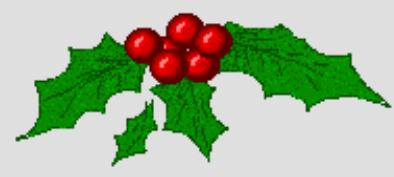


Toodud jutt on üles kirjutatud 1889. aastal Rõngu kihelkonnas Tartumaal ning paikneb Eesti Rahvaluule Arhiivis J. Hurda kogus. Üle Eesti on kirja pandud sama jututüübi (AT 840) veerandsada varianti, mis erinevad nii raamjutustuse (kes, millal ja kuidas satub öömaja otsima ja nägemusi nägema) kui ka nägemuste ja nende seletuste poolest. Lätlaste, leedulaste, soomlaste, liivlaste ja idaslaavlaste variandid sisaldavad veel olulisemaid erinevusi. Kõige sagedamini on jõulud tegevusajaks eestlastel.

Vana uskumuse kohaselt said loomad jõuluööl inimkeeli kõnelda ja peale selle oli neil tulevikunägemise võime. Inimesi hoiatati siiski, et nad ei läheks kuulama. Paljasõnaline keeld ei mõju inimestele, nagu igaüks kindlasti oma kogemustest teab. Keeldude tõhusust on püüdnud suurendada hoiatusjutud, nagu näiteks kaks järgmist:

Üks peremees kuulnud, et loomad kõnelevad uueaasta öösi. *1 Peremees tahtnud näha, kas räägivad. Keegi küsinud pulli käest, kas tal on veel süüa. - Paljas hääl kostnud, mees ei saanud näha, kes küsis. - Pull ütelnud: "Minul ei tule söögipuudust. Mul on kolm vakka teri õlgedes." Peremees tahtnud näha, kas on õige. Ta peksnud õled ja saanudki kolm vakka teri. - Ise jäänud ta tollest ajast kuulmatuks /= kurdiks/.

E, StK 34, 125/6 (39) < Kursi < Põlva - P. Berg /= P. Ariste/ (1926)

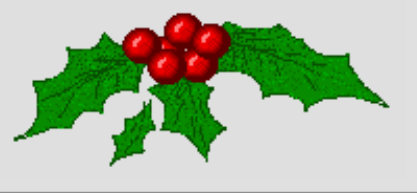

Teine muistend on veel hirmutavam.

Iga Jõulu laupa öösel kell kaksteist pidavat hobused rääkima. Kunagi läinud üks noormees, kes hobuste juttu kuulda tahtnud, Jõululaupa öösel hobuste lauda augu äärele ja jäänud ootama. Äkki kuulnud ta, kuidas üks hobustest magama langenud ja ohkanud: "Millal meil, hobustel, aega on, mina pean homme hommikul peremehe ja -naise kerku sõitma." Teine langenud magama ja öölnud: "Mina pean hakkama homme karjanaisega kajust vett vädama, minu vaevast saavad kõik loomad ja pererahvas elada." Kolmas langenud magama ja öölnud: "Jah! Mina pean selle viimase/l/ püha/l/ surnuaeda viima, kes paergus augu äärel kuulab." Seda kuuldes jooksnud noormees

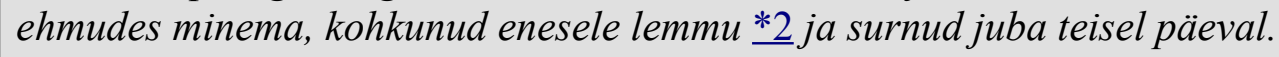
Ning tema maetud viimasel pühal, nagu hobu seda oli ette rääkinud. ERA II 132, 608/9 (37) < Karja khk, Leisi v, Linnuse $\mathrm{k}<$ Jaani khk - A. Jakobson $<$ Marie Pauts, 50 a. (1936).

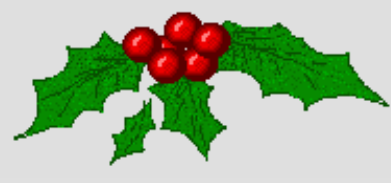


Paljude Euroopa rahvaste, sealhulgas ka eestlaste hulgas olid levinud Jeesuse sünnist ja lapsepõlvest jutustavad lood. Need on rahvapärased täiendused Uuele Testamendile. Järgnev jutt laiendab Matteuse evangeeliumi 2. peatüki 13-15 salmis leiduvat teadet Joosepi, Maarja ja väikese Jeesuse põgenemisest Egiptusesse kuningas Heroodese eest.

\section{Jeesuse esimene imetegu}

Kui Joosep ja Maria põgenesid Herodese eest Jeesusega, siis nendel põlnd kuskilt öömaea saada. Aga nad leidsid ühe kaljukoopa ja läksid sinna sisse. Noor naine tuli nendele seal vastu ja ütles, et ta ei saa võeraid siia vastu võtta. Joosep küsis siis: "Kas teil on nii palju inimesi, et põle ruumi?" Naine ütles: "Jah, kui meie mehed kodu tulevad, siis on meil palju inimesi." Maria hakkas kohe kartma, mis maja nisuke on, noor naine üksi ja palju mehi. Aga Joosep jähi siiski öömaeale.

Sellel naisel oli ka laps, aga see laps oli aiglane. Suur poiss oli juba, kuid ei käind ja oli kärnas. Õhtu Maria tahtis Jeesusele vanni teha ja küsis naise kääst sooja vett. Naine andis ka lahkesti talle. Et sooja vett järele jähi, siis Maria soovitas, et naine eese last ka peseks. Naine ütles: "Ei, ma tohi eese last mette näidatagi, ta nii ull ja kärnas, sul nii ilus poeg." Aga nii kui ta sai oma lapse vanni pannud, kus Jeesust enni sees pesti, kohe laps aeand ennast sirgeks ja kärnad kadund ära.

Õhtu röövlipealik tuleb meestega koju ja poiss jookseb talle vastu: "Isa, ma sain terveks!" Isal ea meel, kudas see juhtus. Siis poeg rääkis ära: "Meil on üks küla naine väikse lapsega. Tema käskis mind pesta oma lapse vannist ja ma sain terveks." Röövlipealikul nii ea meel, tänas veel Mariat ja Joosepit ja andis neile oma mehi kaitseks kaasa, sest seal ümbruses oli palju röövleid.

Õhtul Maria nendele mudugi rääkis, et temal on tõotatud laps ja röövlivanemad akkasid Jumalat uskuma ning jätsid oma kurja ameti maha.

Teise öösi põlnd Marial ja Joosepil jälle peavarju. Siis nad leidsid ühe suure puu ja olid seal all. Ö̈̈si akkas kangesti sadama, siis puu lasknd oma lehed longu nende katteks. Nüid see puu, millel lehed longus, selle all on Jeesus olnd.

Röövlivanemad jätsid küll röövimise maha, aga poeg kasvas ja akkas uuesti seda tööd tegema. Siis kui Jeesus oli ristisambal ja röövel tema kõrvas ja tema eest kostis, sest et ta Jeesuse ära tundis ja mäletas, mis ead ta temale oli teinud.

ERA II 189, 399/401 (5) < Martna khk < Lääne-Nigula khk, Palivere v, Allikma k - E. Ennist $<$ Liisa Alliksoo, snd 1886. a. (1938)

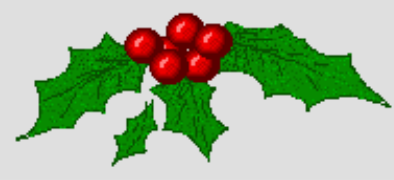


Järgmise jutu tegevus toimub jälle jõuluõhtul. Seda, et inglid üksijäetud last valvavad, tuleb ette ka teistsugustes juttudes, mis pole jõuludega seotud. Jutustaja on antud puhul edastanud enda meelest mitte muinasjuttu või mingit muud ennemuistset lugu, vaid tõsielujuhtumit. Usaldatavust lisavad koha- ja ajamäärang - koolimajas toimuv jõulupidu - ja argised detailid, muuhulgas kurja mehe robustne kõneviis.

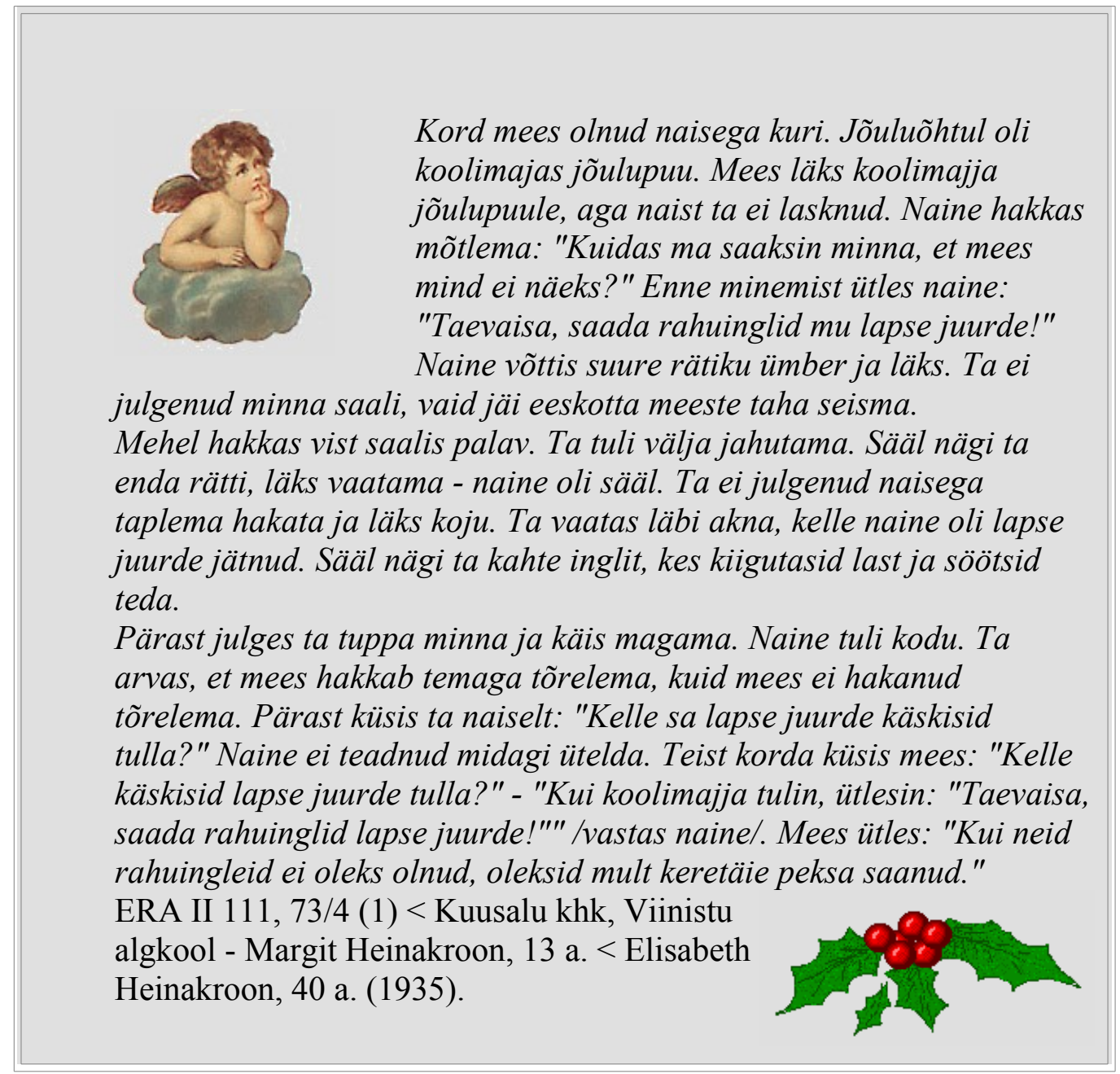

Kunagi, nii sada aastat või veidi vähem tagasi, oli kombeks avaldada suurteks pühadeks erilisi albumeid, mille jaoks kirjutatigi erilisi jutte. Neid anti eesti keeleski välja ja nn jõulujutte, mis reeglina pidid õnnelikult lõppema, on kirjutanud ka eesti kirjanikud. Nii järgib meie elektrooniline jõulualbum kenasti vana tava. Leidku ta lahket lugemist!

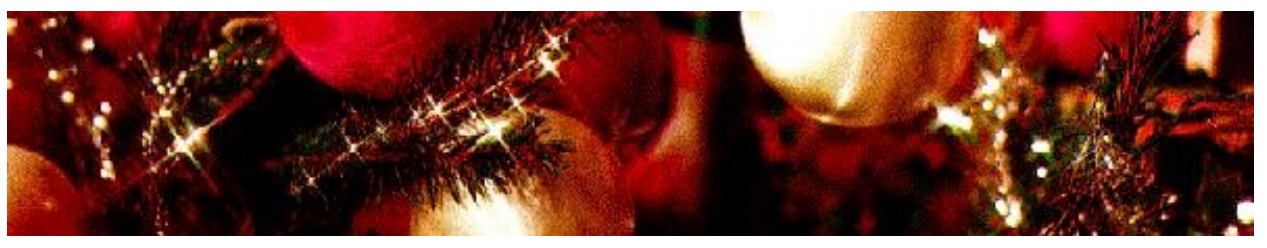

*1 Selle jutu teisendites on enamasti nimetatud ikka jõuluööd. Võiks veel nimetada, et üsna vanasti olid jõulud ühtlasi aastavahetuspühad ning et hiljem, kui aasta lõppu hakati lugema 31. detsembrist 
ja uue algust 1. jaanuarist, nimetati neid aastavahetuspühi ka uuteks jõuludeks.

*2 lemm, lemmtõbi - rahvameditsiinis tuntud haigus, mida on raske üheselt mingi tänapäeva meditsiini määratletud haigusega samastada, kuid mida arvati enamasti surmaga lõppevat. 